OPEN ACCESS

Edited by:

Michael Sweet,

University of Derby, United Kingdom

Reviewed by:

Charles Alan Jacoby,

St. Johns River Water Management

District, United States

Carolina Bastidas,

Massachusetts Institute

of Technology, United States

*Correspondence:

Aschwin H. Engelen aengelen@ualg.pt Pedro R. Frade prfrade@ualg.pt

Specialty section: This article was submitted to

Coral Reef Research,

a section of the journal

Frontiers in Marine Science

Received: 01 June 2018 Accepted: 08 October 2018

Published: 06 November 2018

Citation:

Engelen AH, Aires T, Vermeij MJA, Herndl GJ, Serrão EA and Frade PR (2018) Host Differentiation and Compartmentalization

of Microbial Communities in the Azooxanthellate Cupcorals

Tubastrea coccinea and Rhizopsammia goesi in the Caribbean.

Front. Mar. Sci. 5:391. doi: 10.3389/fmars.2018.00391

\section{Host Differentiation and} Compartmentalization of Microbial Communities in the Azooxanthellate Cupcorals Tubastrea coccinea and Rhizopsammia goesi in the Caribbean

\author{
Aschwin H. Engelen 1,2*, Tânia Aires ${ }^{1}$, Mark J. A. Vermeij ${ }^{2,3}$, Gerhard J. Herndl14,5, \\ Ester A. Serrão ${ }^{1}$ and Pedro R. Frade ${ }^{1,2 *}$ \\ ${ }^{1}$ CCMAR-CIMAR Centre of Marine Sciences, Universidade do Algarve, Faro, Portugal, ${ }^{2}$ CARMABI Foundation, Willemstad, \\ Curaçao, ${ }^{3}$ Aquatic Microbiology, Institute for Biodiversity and Ecosystem Dynamics, University of Amsterdam, Amsterdam, \\ Netherlands, ${ }^{4}$ Department of Limnology and Bio-Oceanography, Center of Functional Ecology, University of Vienna, Vienna, \\ Austria, ${ }^{5}$ Department of Marine Microbiology and Biogeochemistry, Royal Netherlands Institute for Sea Research, Utrecht \\ University, Den Burg, Netherlands
}

We investigated the microbial communities associated with surface mucus layer, tissue, and gastrovascular cavity of two azooxanthellate Caribbean cup corals (Tubastrea coccinea and Rhizopsammia goesi) to explore potential differences in microbial community composition within and among these azooxanthellate scleractinian corals. Using next-generation sequencing of the V3-V6 region of the 16S rRNA gene we found that while alpha-diversity was overall very similar, the relative abundance of microbial taxa differed between host species and among locations within a polyp (i.e., compartments). The interspecific differentiation of microbial assemblages is only challenged by the relatively high similarity among mucus samples of both species. This suggests a stronger signal of the surrounding environment and weaker host control over the mucus compartment compared with the tissue and gastrovascular cavity. $T$. coccinea harbored four indicator OTUs (including a Pseudoalteromonas species, an unidentified Gammaproteobacteria, an unidentified OTU in the family Comamonadaceae and one in the genus Burkholderia). The single indicator for $R$. goesi was another undetermined OTU in the Comamonadaceae. The microbial communities of the gastrovascular cavity and the mucus overlapped substantially in indicator OTUs. None of these were exclusive of the gastrovascular cavity or mucus, while an OTU of the order Thiohalorhabdales occurred uniquely in the tissue. In contrast to the gastrovascular cavity and mucus, the tissue of both coral species was rich in chloroplasts of different algal taxa (mainly Ulvophyceae and Stramenopiles), and an OTU of the genus Roseivirga (family Flammeovirgaceae). The two coral species shared most indicator OTUs for microbial communities residing in their mucus and tissue, but not in their gastrovascular cavities. However, Endozoicomonadaceae occurred in the tissue of both coral species. 
The genus Pseudomonas was found in $R$. goesi but was virtually absent in $T$. coccinea. This study demonstrates the influence of coral compartments and species identities on the composition of microbial communities associated with azooxanthellate cup corals and emphasizes the important effects of within-polyp microhabitats in structuring the coral microbiome.

Keywords: Tubastrea coccinea, microbiome, mucus, gastrovascular cavity, tissue, Rhizopsammia goesi, Curaçao

\section{INTRODUCTION}

As foundation organisms, corals form the ecological and constructive base of coral reefs, which are amongst the most productive marine ecosystems on the planet. The biology of corals has been progressively better understood from a holobiont perspective (Rohwer et al., 2002), that considers their associated microorganisms as integral determinants of the health and survival of coral colonies (Bourne et al., 2016). Historically, most research on microorganisms residing in corals was focused on endosymbiotic dinoflagellates of the family Symbiodiniaceae (zooxanthellae). More recently, the role of prokaryotic members of the coral microbiome has been increasingly studied. Members of the Alphaand Gammaproteobacteria, Actinobacteria, Bacteroidetes, and Cyanobacteria appear to dominate coral prokaryotic microbiomes (Ainsworth et al., 2015; Bourne et al., 2016). In general, the microbial communities of corals are commonly host species-specific but also exhibit variation across biogeographic regions and environmental conditions (Hernandez-Agreda et al., 2016; Glasl et al., 2017). While at the scale of the colony, coral microbiomes are generally stable over time in the absence of major environmental change, this does not imply that their composition is uniformly distributed within individual coral polyps.

The mucus, tissue, gastrovascular cavity, and skeleton all form distinct specific micro-habitats, that can harbor different microbial communities providing various benefits to their coral host (Agostini et al., 2012; Ainsworth et al., 2015; Marcelino and Verbruggen, 2016). For example, microbes residing in the surface mucus layer of corals (e.g., Photobacterium, Endozoicimonaceae, and Firmicutes) can provide nutritional benefits to their hosts (Wild et al., 2004), protect them against pathogens through the production of antibiotics and/or occupation of specific niches (Ritchie, 2006; Glasl et al., 2016) and reduce the damaging effects of ultraviolet radiation (Ravindran et al., 2013). Members of the microbial Actinobacteria, Ralstonia, and Endozoicomonas are commonly found in coral tissue (Bayer et al., 2013; Ainsworth et al., 2015; Neave et al., 2016, 2017). Similar to the human gut, the microbiome in the gastrovascular cavity of a coral is thought to catabolize ingested organic matter, recycle nutrients and provide vitamins to their hosts (Agostini et al., 2012). Coral skeletons contain endolithic microalgae (Shashar et al., 1997; Marcelino and Verbruggen, 2016), bacteria (Yuen et al., 2013) and fungi (Bentis et al., 2000), of which some are considered beneficial to the coral host. For example, bleached corals can benefit from the presence of the endolithic alga Ostreobium that provides food to corals in the form of photosynthates after the algal endosymbionts have become expelled from the corals in response to elevated water temperatures (Fine and Loya, 2002).

Reef-building scleractinian corals and their microbiomes have been fairly well studied, particularly the endosymbiotic photoautotrophic community of eukaryotic microbes in the family Symbiodiniaceae (e.g., Kirk and Weis, 2016). Only rare studies, however, have focused on the microbiomes of azooxanthellate scleractinian corals, even though these corals account for one-third of all contemporary scleractinian species (Cairns, 2007; Roberts et al., 2009). Because azooxanthellate corals are the most basal extant scleractinians (Kitahara et al., 2010) the relationships they establish with microbes could be of interest to provide insights into the evolution of coral holobiont composition and functioning. Azooxanthellate corals obtain their energy exclusively through heterotrophic feeding and likely this has consequences for the lifestyle of their associated prokaryotic communities (Littman et al., 2010; Brener-Raffalli et al., 2018). Compared to zooxanthellate corals, azooxanthellate corals are characterized by larger distribution ranges, being found in all oceans from Antarctica (Cairns, 1982) to the Arctic (Roberts et al., 2009). Azooxanthellate corals also inhabit a wide spectrum of habitats, from shallow tropical waters to depths beyond 6,300 m (Keller, 1976), and they can even thrive under temperatures as low as $-1^{\circ} \mathrm{C}$ (Vaughan and Wells, 1943). Due to their wide environmental tolerances as compared with zooxanthellate corals, azooxanthellate corals are capable of invading new areas relatively easily as exemplified by the relatively recent invasion of the Southwestern Atlantic by the Pacific species Tubastraea coccinea and T. tagusensis (Cairns, 2000; Creed et al., 2017).

In this study, we test the hypothesis that different polyp compartments (i.e., different functional areas or microhabitats within a coral polyp) of two azooxanthellate coral species harbor different microbial communities and that these compartment differences are pervasive across host species. To test this hypothesis, samples were collected from the surface mucus layer, tissue, and gastrovascular cavity of two common azooxanthellate sun corals in the Caribbean (T. coccinea and Rhizopsammia goesi) that co-occur on the fringing reefs around the island of Curaçao in the Southern Caribbean. T. coccinea is an invasive species whose expansion throughout the Caribbean has been well documented (Cairns, 2000; Creed et al., 2017), whereas $R$. goesi, a species invading more exposed areas on the reef, is an Atlantic species that is currently increasing in abundance 
around the island of Curaçao (Vermeij and Engelen pers. observ.).

\section{MATERIALS AND METHODS}

\section{Field Collections}

Samples of T. coccinea (Lesson, 1830) and R. goesi (Lindström, 1877) (Supplementary Figure S1) were collected from approximately $20 \mathrm{~m}$ depth between February 1st and 8th in 2014 from the reef near the Holiday Beach Hotel in Curaçao $\left(12.106582^{\circ},-68.948753^{\circ}\right)$. In total thirty specimens were sampled from an area of ca. $50 \mathrm{~m} \times 50 \mathrm{~m}$. For each specimen three different compartments (within a polyp) were sampled in situ using different techniques; (1) the surface mucus layer was sampled by gently rolling a sterile cotton swab over the polyp's surface; (2) the contents of the gastrovascular cavity were sampled using a $1 \mathrm{ml}$ syringe with blunt needle to avoid perforation of the epithelia resulting in a sample volume between 200 and $900 \mu \mathrm{L}$, which likely also included some surrounding seawater; finally, (3) the whole polyp was removed with a spatula to sample the microbiome associated with the cupcoral tissue and for host identification (via corallite characteristics and DNA barcoding). Reference sediment samples $(n=6)$ and ambient seawater $(n=2)$ were taken from the vicinity of the sampled corals. Sediment was collected from the superficial layer into $2 \mathrm{~mL}$ tubes whereas each seawater sample consisted of $2 \mathrm{~L}$ collected in Plexiglas cylinders. Whole polyps were then rinsed in the laboratory with $0.22-\mu \mathrm{m}$-filtered seawater to remove loosely attached microbes. Coral and sediment samples were flash-frozen in liquid nitrogen within $30 \mathrm{~min}$ after collection and stored at $-80^{\circ} \mathrm{C}$ until further processing. Seawater samples were filtered onto $0.22-\mu \mathrm{m}$ polycarbonate filters (GTTP, Millipore) and flash-frozen within $2 \mathrm{~h}$ after collection. When polyps were thawed (preceding DNA extraction) they were rinsed with milliQ to remove as much mucus as possible and reduce carry over of mucus microbes into the tissue samples. Research on Curaçao was performed under the annual research permit (48584) issued by the Curaçao Ministry of Health, Environment and Nature (GMN) to the CARMABI Foundation.

\section{DNA Extraction and Sequencing}

DNA was extracted from each individual sample using the FastDNA SPIN Kit for Soil (MP Biomedicals) following the manufacturer's protocol. To sample the microbiome of the tissue compartment, a small portion of the coenosarc of each sample was removed with a scalpel blade and used for DNA extractions, avoiding the inclusion of possible mucus residue remaining on the sample. To identify the sampled cup corals to species level, their 28S rRNA gene was sequenced after amplification using the primers $\mathrm{Cl}^{\prime}\left(5^{\prime}\right.$-ACC CGC TGA ATT TAA GCA T-3') and D2MAD ( $5^{\prime}-$ GAC GAT CGA TTT GCA CGT CA- $\left.3^{\prime}\right)$ and following PCR conditions as in Cuif et al. (2003). This method produced 861-bp fragments, blasted against the NCBI database and submitted there under accession numbers ${ }^{1}: \mathrm{X}$. R. goesi could

${ }^{1}$ https://figshare.com/s/ffa8955c44ad93ce2023 not be identified molecularly due to lack of sequence data in public databases. We therefor rely on the visually identification by Bert Hoeksema (Naturalis Biodiversity Center, Netherlands; see Hoeksema and ten Hove, 2017).

To identify the microbiome of aforementioned samples, DNA extracts of 22 samples (i.e., $n=3$ per compartment per host species, plus $n=2$ for each reference habitat: sediment and seawater) were sent to the IMGM laboratories (Planegg, Germany) for sequencing. 728-bp fragments with variable regions V3-V6 of the archaeal and bacterial 16S rRNA gene were sequenced using 454 GL FLX+ technology (Roche) after PCR amplification using primers U341F (5' - CCT ACG GRA GGC AGC AG. - $3^{\prime}$ ) and U1053R (5' - CTG ACG RCR GCC ATG C $3^{\prime}$ ) adapted by IMGM laboratories from Wang and Qian (2009). Each $25 \mu \mathrm{L}$ of PCR reaction consisted of $1 \times$ Taq buffer, $3 \mathrm{mM}$ $\mathrm{MgCl}_{2}, 2 \mathrm{mM}$ (of each) dNTP, $0.2 \mathrm{mg} \mathrm{mL}^{-1}$ BSA, $0.25 \mu \mathrm{M}$ of each primer, $0.03 \mathrm{U} \mu \mathrm{L}^{-1}$ of Taq DNA Polymerase (Fermentas) and 1-2 $\mu \mathrm{L}$ of template DNA. Cycling conditions consisted of $4 \mathrm{~min}$ at $95^{\circ} \mathrm{C}$ for initial denaturation, followed by 30 cycles performed at $95^{\circ} \mathrm{C}$ for $30 \mathrm{~s}, 65^{\circ} \mathrm{C}$ for $45 \mathrm{~s}$ and $72^{\circ} \mathrm{C}$ for $90 \mathrm{~s}$. A final elongation step at $72^{\circ} \mathrm{C}$ for $10 \mathrm{~min}$ completed each reaction. PCR products were evaluated through electrophoresis on $1.5 \%$ agarose gels. The 22 samples sent for sequencing included two sediment and two seawater samples, plus 18 cup coral samples, representing three individual specimens for each of the two cup coral species comprising the three host compartments within each specimen.

\section{Microbiome Analyses}

Sequencing reads were demultiplexed and denoised in QIIME (version 1.9.0; Caporaso et al., 2010a) using a sliding window test of quality scores and a minimum Phred score of 25, after which primers were removed. Chimeric sequences were also removed using usearch61 (Edgar, 2017) with both de novo and referencebased detection as implemented in QIIME. A total of 135,524 reads with an average length of 620-bp passed all quality filtering steps and were successfully clustered into OTUs using a closed reference OTU picking method based on a $97 \%$ similarity cutoff value excluding singletons. Representative OTUs were picked and aligned with PyNAST (version 1.2.2; Caporaso et al., 2010b) against the Greengenes database (version 13.5), and taxonomy assigned using uclust as implemented in QIIME. Rare OTUs (comprising less than $0.005 \%$ of all sequences) were removed because they are often associated with spurious sequencing reads (Bokulich et al., 2013).

Analyses of alpha- and beta-diversity of retrieved microbial communities were performed on relative abundance data at the OTU level using the R packages "vegan," "labdsv," "MASS," "cluster," “indicspecies," “permute," “dplyr," “tidyr," “ggplot2," and "RColorBrewer" (R Development Core Team, 2013). In order to correct for varying sequencing efforts, data were rarefied to the minimum number of reads: 789 sequences. Samples had on average 6558 reads (range: 789-16,105). OTU richness and Shannon-Weaver diversity were compared amongst samples using Analysis of Variance (ANOVA). Nonmetric Multidimensional Scaling ordination (nMDS, after 9999 permutations) was used to visualize the variation in community 
structure amongst habitats, host species, and host compartments, based on Bray-Curtis dissimilarities among samples. The null hypothesis of no difference in the microbial community structure among sampling groups was tested using Permutational Multivariate Analysis of Variance (PERMANOVA; 9999 permutations), after the homogeneity of multivariate dispersion was confirmed with PERMDISP, a betadispersion measure. These were computed, respectively, with the adonis and betadisp functions in the "vegan" $\mathrm{R}$ package. Indicator Values analysis (IndVal) was used to identify the OTUs significantly associated with the different habitats, hosts and compartments, or groups thereof, based on their specificity and fidelity to particular sampling group(s) (De Cáceres and Legendre, 2009). Specificity is the probability that the OTU belongs to that particular sampling group and not to other groups, whereas fidelity is the probability of finding the OTU in the different samples of that sampling group. OTUs are considered significantly associated $(p<0.05)$ when both specificity and fidelity have probabilities above 0.5 . This approach has in the past been used to identify microbial indicators of particular coral compartments (Li et al., 2014), particular depth habitats on a coral reef slope (Glasl et al., 2017) or particular coral health states after environmental disturbance (Glasl et al., 2016).

All demultiplexed 16S rRNA gene raw reads and sampling metadata are available in the NCBI Sequence Read Archive database $^{2}$ under BioProject accession number PRJNA494429.

\section{RESULTS}

A total of 131,173 reads clustering into 1040 non-spurious OTUs were included in our statistical analyses. Two of the three samples originating from the gastrovascular cavity of $T$. coccinea had only one and ten reads, respectively, and were therefore removed from the analyses. Although sample size precluded making statistical comparisons that include the sediment and seawater samples ( $n=2$ for each), there were no obvious differences in OTU richness among sediment (121-124 OTUs), seawater (122-125 OTUs) and the coral samples (mean: 127 OTUs, SD: 38). OTU richness was similar between the two cup coral species (OTUs; $F_{(14,1)}=0.699, p=0.417$ ) and compartments (OTUs; $\left.F_{(13,2)}=0.053, p=0.949\right)$. Shannon-Weaver diversity of all samples followed the same pattern, with values of 3.39-3.55 for sediment and 3.49-3.51 for seawater, and 3.59 \pm 0.56 for the coral samples. Diversity did not differ between species $\left(F_{(14,1)}=1.408\right.$, $p=0.255)$ or among host compartments $\left(F_{(13,2)}=0.503\right.$, $p=0.616)$. Therefore, the number of OTUs identified within each sample cannot explain potential differences in beta-diversity (addressed below).

Microbial community structure differed between both coral species (PERMANOVA, pseudo $F_{(12,1)}=1.694$, $p=0.040$ ) and among compartments (pseudo $F_{(12,2)}=1.557$, $p=0.032$, Figure 1). Interaction between host species and compartment was not significant $\left(F_{(10,2)}=1.486, p=0.076\right)$. Multivariate dispersions were homogeneous between host

${ }^{2}$ http://www.ncbi.nlm.nih.gov/sra/

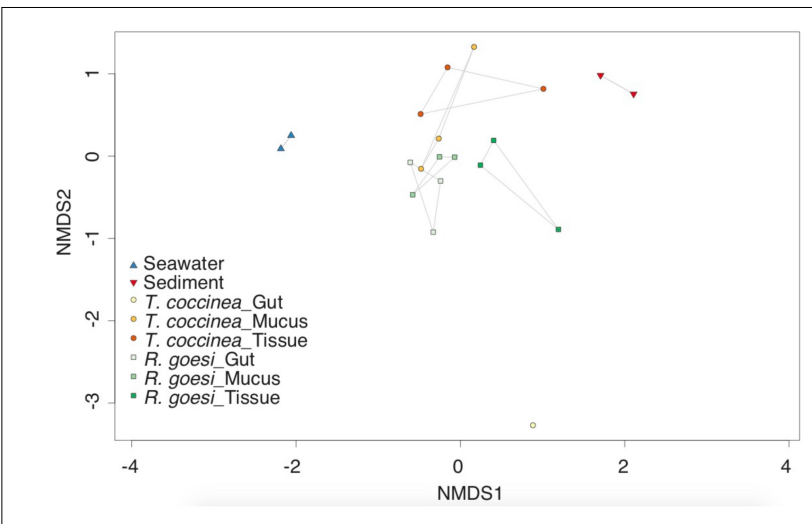

FIGURE 1 | Two-dimensional non-metric multidimensional scaling (nMDS) ordination depicting variation in microbial community structure among the cup corals Rhizopsammia goesi and Tubastrea coccinea across polyp compartment: surface mucus layer, tissue, and gastrovascular cavity (or "gut"). Seawater and sediment samples added as reference to all plots. Polygons delimitate the distribution of each sampling group within the nMDS.

species (PERMDISP $\left.F_{(14,1)}=2.962, p=0.107\right)$, and among compartments $\left(F_{(13,2)}=0.840, p=0.454\right)$. Microbial community structure of the mucus partly overlapped with both the gastrovascular and tissue community (Figure 1), however, the latter two compartments were more dissimilar from one another than they were from mucus. The gastrovascular cavity of T. coccinea appears to possess a unique microbiome, though this is based on only one sample (Figure 1), making it impossible to perform statistical comparisons including this sampling group. Samples from the gastrovascular cavity of $T$. coccinea consistently yielded low number of reads, suggesting that a low microbial biomass in this compartment could have resulted in the observed unsuccessful sequencing of its microbiome. Community analysis using presence/absence data also showed differentiation among the cup corals and compartments as described above based on abundance distribution data.

Microbiomes were very diverse in each species vs. compartment combination and the 20 most abundant OTUs accounted for about half of the reads across all samples (44\% on average; Figure 2). Seawater was dominated by a range of distinct OTUs belonging to the family Pelagibacteraceae, as well as the genera Synechococcus and Prochlorococcus (family Synechococcaceae). Chloroplast DNA-derived and Cyanobacteria dominated sediment microbiomes, whereas cup coral samples were characterized by several OTUs of the genus Ralstonia, one OTU of the genus Cupriavidus (both in the family Oxalobacteraceae) and several OTUs from the family Comamonadaceae. The single sample of the gastrovascular cavity of $T$. coccinea had a quite unique microbiome, which was dominated by many evenly abundant OTUs (Figure 2B) from the genus Hymenobacter (family Cytophagaceae), the families Syntrophobacteracea and Rhyzobiaceae, and an unidentified Acidobacteria. Compared with $R$. goesi, T. coccinea harbored, in general, more Gammaproteobacteria (including an abundant Pseudoalteromonas OTU, Figure 2A). Chloroplasts of different algal taxa (Ulvophyceae and Stramenopiles) and an OTU of the 


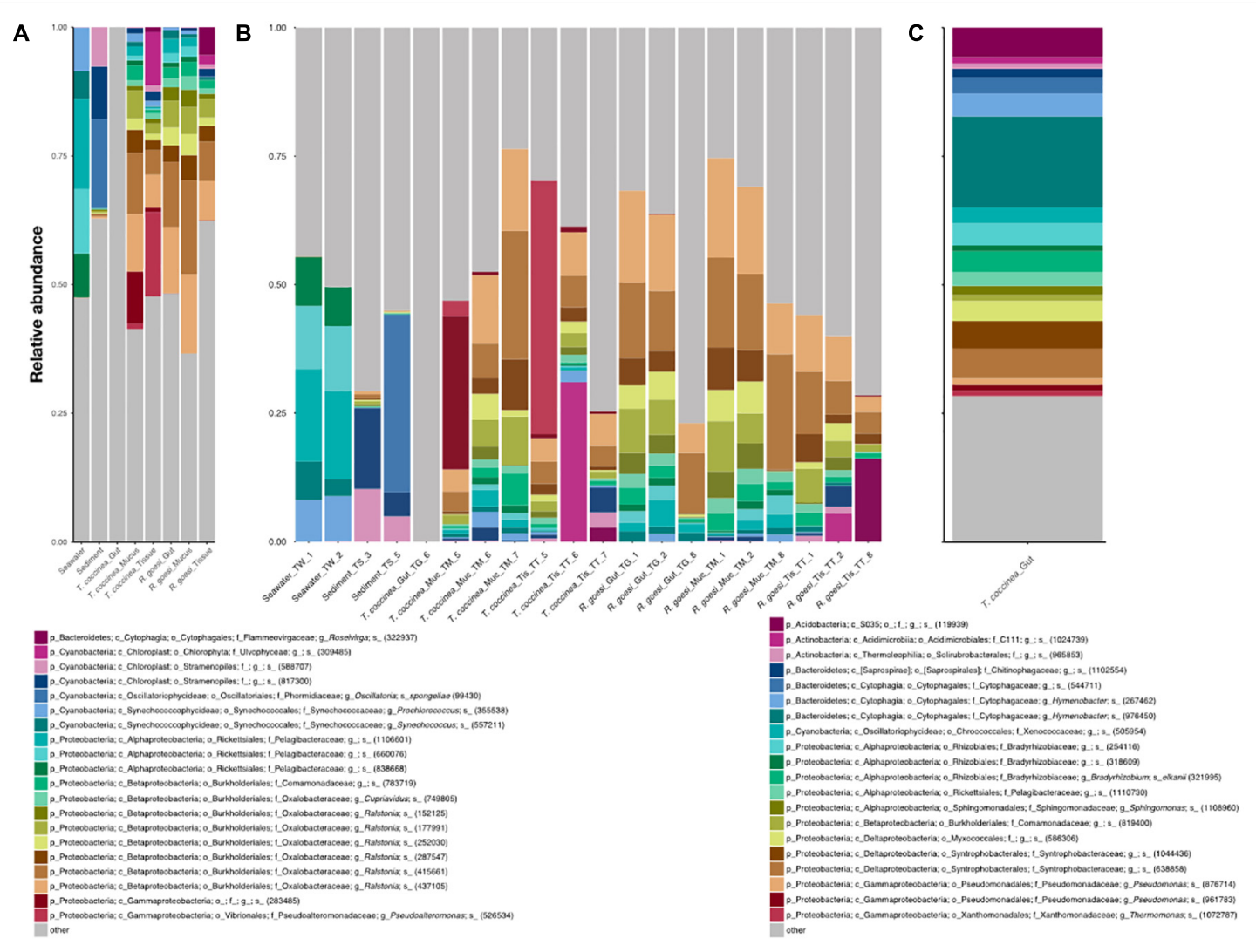

FIGURE 2 | Microbial community composition (relative abundance) resolved for (A) the seawater, sediment, and the cup corals $R$. goesi and T. coccinea across their surface mucus layer, tissue, and gastrovascular cavity (or "gut"), based on partial 16S rRNA amplicon sequencing. Only the 20 most abundant operational taxonomic units (OTUs) are depicted and the remainder pooled into "others"; (B) shows the same results but for each individual sample; (C) shows the particular community composition for the gastrovascular cavity of T. coccinea, which did not share any of the 20 most abundant OTUs with the other sampling groups. Affiliation of each OTU shows its lowest identified taxonomic rank: (p) phylum, (c) class, (o) order, (f) family, (g) genus, and s (species), plus an OTU code (within brackets).

genus Roseivirga (family Flammeovirgaceae) were largely absent in the gastrovascular or mucus compartments ( $\leq 1 \%$ of reads) but dominated the tissue of both cup coral species (with a combined average of 10 and $14 \%$ of the reads for R. goesi and T. coccinea, respectively). Archaea (e.g., phylum Euryarchaeota) comprised less than $1 \%$ of the total reads from all three coral compartments and accounted on average for 3.1 and $0.9 \%$ of all reads from seawater and sediment samples, respectively.

Based on indicator value analysis, five OTUs emerged as indicators of both cupcoral species (as compared to the environmental samples): four distinct OTUs of the genus Ralstonia and one of the genus Cupriavidus (Figure $3 \mathbf{A}$ ). Some of these OTUs were also present in the sediment samples but are not characteristic for this habitat as they did not occur in both samples. None of the microbial indicator OTUs of the cup coral species were present in the seawateryl. The analysis recognized four OTUs as indicators for T. coccinea: a Pseudoalteromonas species, an undetermined Gammaproteobacteria, an undetermined OTU of the family Comamonadaceae and one of the genus Burkholderia. The single indicator OTU recognized for $R$. goesi was an undetermined member from the family Comamonadaceae. Irrespective of cup coral species, the gastrovascular and mucus microbiomes exhibited substantial overlap in indicator OTUs (Figure 3B), including OTUs from the family Pelagibacteraceae, which were also typical indicators for the sampled seawater microbiome, and from the genus Ralstonia, which were also indicators of the sampled sediment microbiome (Figure 3B). While there were no exclusive microbial indicators identified for either the gastrovascular cavity or the mucus compartment (Figure 3B), the microbiome in the tissue compartments (of both coral species) contained an unique OTU affiliated to the order Thiohalorhabdales.

The two species of coral shared most of the indicator OTUs for the mucus compartment (Figure 3C) but not for the two other compartments. This was particularly evident for the gastrovascular cavity, where the community associated with $T$. coccinea greatly differed from the community in $R$. goesi, as well as from the microbiomes associated with all other species vs. compartment combinations. Since we only had a single sample from the gastrovascular cavity of $T$. coccinea, it becomes irrelevant to identify exclusive indicators for this sampling group. However, Endozoicomonadaceae proved to be significant indicators of the tissue of both coral species and 


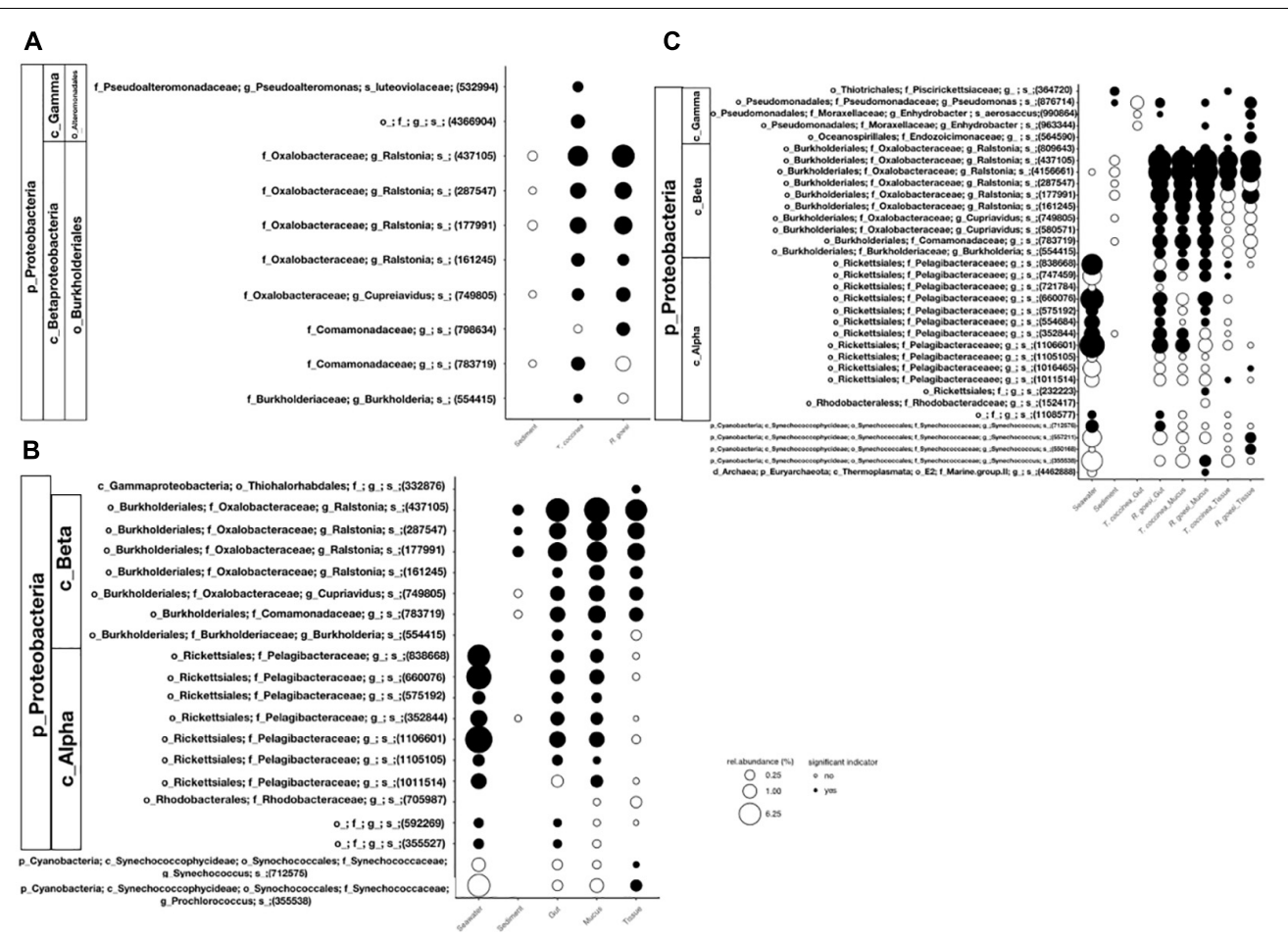

FIGURE 3 | Mean relative abundance of microbial indicator OTUs associated with (A) the cup corals R. goesi and T. coccinea, (B) the polyp compartment: surface mucus layer, tissue, and gastrovascular cavity (or "gut"), and (C) each species vs. polyp compartment combination. Seawater and sediment indicator OTUs are also shown when shared with any of the other sampling groups. Indicator taxa were identified with Indicator Value Analysis to be significantly associated with a certain sampling host or polyp compartment (indicated by black filled-in circles). Exclusive indicators for seawater, sediment or the gut of $T$. coccinea (in $\mathbf{C}$ ) are not show. Affiliation of each OTU shows its lowest identified taxonomic rank: (p) phylum, (c) class, (o) order, (f) family, (g) genus, and s (species), plus an OTU code (between brackets).

the genus Pseudomonas was an indicator of all compartments of $R$. goesi, but rarely found in T. coccinea (except in the one gastrovascular sample successfully sequenced).

\section{DISCUSSION}

In this study, we reveal drivers of microbiome variation in azooxanthellate, heterotrophic scleractinian corals, by showing consistent differences in the microbiomes associated with the microhabitats formed by three distinct polyp compartments and for two different coral species: $T$. coccinea and $R$. goesi. Such intra-polyp microhabitat differences in microbial community structure had never been shown for tropical azooxanthellate cup corals. Our results showing that the microbial communities associated with these two tropical cup corals differed by coral species and polyp compartment are similar to patterns described for tropical and non-tropical reef-building scleractinian corals (e.g., Agostini et al., 2012). Some bacterial genera present in the microbial communities of $T$. coccinea and $R$. goesi, such as Endozoicomonas and Ralstonia, have been reported as important members of coral-associated bacterial communities (discussed below). However, further conclusions are restricted due to missing replicates, as only one of our three samples of the T. coccinea gastrovascular cavity provided reads.
The associated microbial communities differ between the two cup coral species, but those differences were smaller than those found between microbial communities residing in the sediment and seawater at the same location. Differences between environmental and macro-organism associated bacterial communities (e.g., Sunagawa et al., 2010; Carlos et al., 2013; Polónia et al., 2014) as well as between different host species (e.g., Aires et al., 2016) are commonly observed in the marine environment (e.g., Sunagawa et al., 2010; Carlos et al., 2013; Polónia et al., 2014). The azooxanthellate cold-water corals Madrepora oculata and Lophelia pertusa from a single location, for example, showed species-specificity of their associated bacterial communities but with interspecific distinct spatial and temporal variation patterns (Meistertzheim et al., 2016).

Our findings furthermore add to the growing body of evidence that different host compartments are also occupied by different microbial communities (e.g., Sweet et al., 2010; Apprill et al., 2016). To the best of our knowledge, this is the first time that such intra-polyp level differences in microbial community structure are shown for tropical azooxanthellate cup corals. The cup coral $T$. coccinea has been included in coral microbiome studies in the past. In Brazil, the overall mucus microbiome community of $T$. coccinea did not differ from that of the scleractinian corals Madracis decactis and Mussismilia hispida. However, $T$. coccinea did harbor three low abundance species-specific 
OTUs belonging to the genera Tenacibaculum and Haliagium and a member of the Alphaproteobacteria (Carlos et al., 2013). Tissue of T. coccinea from the East China Sea was dominated by Betaproteobacteria (81\%), Gammaproteobacteria $(6 \%)$ and Cyanobacteria (5\%) (Yang et al., 2013). Bacteria potentially active as denitrifiers and ammonium oxidizers were present, suggesting bacteria mediated nitrogen cycling in $T$. coccinea (Yang et al., 2013). The mucus microbiome of the Caribbean Porites astreoides (a mucus shedding species) showed shifts in prokaryotic community composition with aging and cycling of the mucus layer (Glasl et al., 2016). To what extent the mucus associated community of cupcorals changes over time remains to be explored.

The family Endozoicomonadaceae contains members of the genus Endozoicomonas which are known as symbionts of a wide variety of benthic marine macro-organisms and have been isolated, for example, from sponges, corals, bivalves, gastropods, and ascidians (Kurahashi and Yokota, 2007; Hyun et al., 2014; Appolinario et al., 2016; Schreiber et al., 2016; Sheu et al., 2017). Despite the fact that Endozoicomonas bacteria are associated with a wide variety of corals across oceanic basins, certain Endozoicomonas OTUs only occur in a single host species (Neave et al., 2016). This highly tuned host-microbe association has been proposed to have evolved through coevolution (Neave et al., 2016). In our study, one out of the 10 Endozoicomonaceae OTUs was unique for T. coccinea tissue and three for $R$. goesi tissue, none were unique within a single species or environmental sample, but an additional three were only detected in the corals. This lack of host species specificity suggests that Endozoicomonas members in sun corals are perhaps less tightly associated with their coral host. Furthermore, their presence in these azooxanthellate corals might still be surprising since Bayer et al. (2013) showed Endozoicomonas cells live in close proximity to zooxanthellae cells within the coral tissue. In our and other studies, Endozoicomonas bacteria were found in azooxanthellate hosts, including the deep cold-water M. oculata (Hansson et al., 2009; Meistertzheim et al., 2016). While their functional role is still unclear, Endozoicomonas might be involved in nutrient acquisition and provision, the structuring of the host microbiome and the health status of the host holobiont (Jessen et al., 2013; Vezzulli et al., 2013; Appolinario et al., 2016; Neave et al., 2016, 2017). Although our Endozoicomonadaceae reads most closely matched Endozoicomonas members, the similarities ranging from 91.9 to $100 \%$ or matching $98-99 \%$ of an uncultured bacteria detected on P. lutea (Séré et al., 2013) suggest they might be undetermined non-Endozoicomonas members of the Endozoicomonadaceae.

The genus Ralstonia was represented by 17 OTUs in our dataset. Eight of the Ralstonia OTUs were highly abundant in both corals across all compartments, but were not exclusively found associated with the corals as they occurred in the sediment as well. Five Ralstonia OTUs were unique to the two coral species, but not species- or compartment-specific and four very low abundance OTUs were coral host-specific. Ralstonia is very common in zooxanthellate corals in the Red Sea (Lee et al., 2012), but also occurs in low abundances in certain coral species from the Caribbean (Sunagawa et al., 2010), the Coral Sea and Hawaii (Ainsworth et al., 2015). Similar to Endozoicomonas, Ralstonia bacteria seem to cooccur intracellularly with zooxanthellaecontaining coral cells (Ainsworth et al., 2015). In addition, Ralstonia sp. accounted for 65 and 53\% of genes associated with transport and amino acid metabolism, respectively, in Acropora granulosa, suggesting an active interaction with the coral host (Ainsworth et al., 2015). Our finding of Ralstonia in azooxanthellate, non-photosynthetic sun corals indicates they do not associate exclusively with photosynthetic organisms.

Various coral microbial studies have been performed around the island of Curaçao, none of them including cupcorals, but they suggest microbial communities of corals differ spatially across different scales. Corals with narrower depth distribution ranges (depth-specialists: Agaricia grahamae and Madracis pharensis) were associated with a stable prokaryotic community, whereas corals with a broader niche range (depth-generalists: Stephanocoenia intersepta) revealed a higher variability in their prokaryotic community (Glasl et al., 2017). The bulk of the microbial community of $P$. astreoides consisting of rare members, differed among locations around Curaçao (Rodriguez-Lanetty et al., 2013). Environmental conditions seem to contribute considerably to these community differences as the largest difference was associated with samples taken closest to the water outlet of the waterfactory of the island. Whether microbial communities of cupcorals exhibit similar patterns remains to be explored.

The rather unique microbiome composition in the gastrovascular cavity of $T$. coccinea shows high similarity to the gut microbiome of crustacean fed Atlantic cup corals (in the genus Caryophyllia), which contain a panoply of known anaerobes and facultative anaerobes (P. Frade, unpublished). This suggests that $T$. coccinea may heavily prey on zooplankton, but we cannot make any conclusive remark due to limitations in our sample size. In contrast, the similarity of microbial communities of mucus and gastrovascular cavity in $R$. goesi could indicate that this species relies more on mucus ingesting than T. coccinea. However, we suggest it is also possible that these differences are caused by the cavity content or time since feeding as the chemical and microbial characteristics in the coral gastrovascular cavity might undergo considerable temporal fluctuation depending on feeding regime (Agostini et al., 2012). This temporal variability and prey dependence of the gastrovascular cavity of corals certainly deserves further research.

\section{CONCLUSION}

In conclusion, in this study we show species and compartment differentiation of microbial communities in two tropical azooxanthellate cup corals. We hope this study will stimulate more holistic studies on these corals considering our limited knowledge, their evolutionary important position, their invasive characteristics and the practical advantages provided by their rather large polyps for manipulative studies. 


\section{AUTHOR CONTRIBUTIONS}

$\mathrm{AE}, \mathrm{MV}$, and $\mathrm{PF}$ designed the study and performed the fieldwork. $\mathrm{PF}$ performed the laboratory work. TA, AE, and PF performed the analyses. All authors contributed to interpretations, manuscript writing, editing, and approved the submitted version.

\section{FUNDING}

This study was financially supported by Fundação para a Ciência e a Tecnologia (FCT, Portugal) in the form of scholarships SFRH/BPD/107878/2015 to AE and SFRH/BPD/110285/2015 to PF, and UID/Multi/04326/2013 to CCMAR. Fieldwork and lab

\section{REFERENCES}

Agostini, S., Suzuki, Y., Higuchi, T., Casareto, B., Yoshinaga, K., Nakano, Y., et al. (2012). Biological and chemical characteristic of the coral gastric cavity. Coral Reefs 31, 147-156. doi: 10.1007/s00338-011-0831-6

Ainsworth, T. D., Krause, L., Bridge, T., Torda, G., Raina, J.-B., Zakrzewski, M., et al. (2015). The coral core microbiome identifies rare bacterial taxa as ubiquitous endosymbionts. ISME 9, 2261-2274. doi: 10.1038/ismej.2015.39

Aires, T., Serrão, E. A., and Engelen, A. H. (2016). Host and environmental specificity in bacterial communities associated to two highly invasive marine species (Genus Asparagopsis). Front. Microbiol. 7:559. doi: 10.3389/fmicb.2016. 00559

Appolinario, L. R., Tschoeke, D. A., and Rua, C. P. J. (2016). Description of Endozoicomonas arenosclerae sp. nov. using a genomic taxonomy approach. Antonie Van Leeuwenhoek 109, 431-438. doi: 10.1007/s10482-016-0649-x

Apprill, A., Weber, L. G., and Santoro, A. E. (2016). Distinguishing between microbial habitats unravels ecological complexity in coral microbiomes. mSystems 1:e00143-16. doi: 10.1128/mSystems.0014316

Bayer, T., Neave, M. J., Alsheikh-Hussain, A., Aranda, M., Yum, L. K., Mincer, T., et al. (2013). The microbiome of the Red Sea coral Stylophora pistillata is dominated by tissue-associated Endozoicomonas bacteria. Appl. Environ. Microbiol. 79, 4759-4762. doi: 10.1128/AEM.00695-13

Bentis, C. J., Kaufman, L., and Golubic, S. (2000). Endolithic fungi in reefbuilding corals (order: Scleractinia) are common, cosmopolitan, and potentially pathogenic. Biol. Bull. 198, 254-260. doi: 10.2307/1542528

Bokulich, N. A., Subramanian, S., Faith, J. J., Gevers, D., Gordon, J. I., Knight, R., et al. (2013). Quality-filtering vastly improves diversity estimates from Illumina amplicon sequencing. Nat. Methods 10, 57-59. doi: 10.1038/nmeth.2276

Bourne, D. G., Morrow, K. M., and Webster, N. S. (2016). Insights into the coral microbiome: underpinning the health and resilience of reef ecosystems. Annu. Rev. Microbiol. 70, 317-340. doi: 10.1146/annurev-micro-102215-095440

Brener-Raffalli, K., Clerissi, C., Vidal-Dupiol, J., Adjeroud, M., Bonhomme, F., Pratlong, M., et al. (2018). Thermal regime and host clade, rather than geography, drive Symbiodinium and bacterial assemblages in the scleractinian coral Pocillopora damicornis sensu lato. Microbiome 6:39. doi: 10.1186/s401 68-018-0423-6

Cairns, S. D. (1982). Antarctic and Subantarctic Scleractinia. Antarct. Res. Ser. 34:74.

Cairns, S. D. (2000). A revision of the shallow-water azooxanthellate Scleractinia of the Western Atlantic. Stud. Nat. Hist. Caribb. 75, 1-192.

Cairns, S. D. (2007). Deep-sea coral ecosystems: biology and geology. Bull. Mar. Sci. 81, 309-310.

Caporaso, J. G., Kuczynski, J., Stombaugh, J., Bittinger, K., Bushman, F. D., Costello, E. K., et al. (2010a). QIIME allows analysis of high-throughput community sequencing data. Nat. Methods 7, 335-336. doi: 10.1038/nmet h.f.303

Caporaso, J. G., Bittinger, K., Bushman, F. D., DeSantis, T. Z., Andersen, G. L., and Knight, R. (2010b). PyNAST: a flexible tool for aligning sequences to a template alignment. Bioinformatics 26, 266-267. doi: 10.1093/bioinformatics/btp636 consumables were covered by Marie Curie fellowship FP7-299320 to PF and the sequencing costs by the Austrian Science Fund (FWF) project P28781-B21 to GH.

\section{SUPPLEMENTARY MATERIAL}

The Supplementary Material for this article can be found online at: https://www.frontiersin.org/articles/10.3389/fmars. 2018.00391/full\#supplementary-material

FIGURE S1 | The studied sun coral species Rhizopsammia goesi (right hand side) and Tubastrea coccinea (left hand side) (A) in situ on the same very shallow reef on Curaçao, Dutch Caribbean during daytime and (B) at night time, showing differences in polyp size.

Carlos, C., Torres, T. T., and Ottoboni, L. M. M. (2013). Bacterial communities and species-specific associations with the mucus of Brazilian coral species. Sci. Rep. 3:1624. doi: 10.1038/srep01624

Creed, J. C., Fenner, D., Sammarco, P., Cairns, S., Caperl, K., Junqueira, A. O. R., et al. (2017). The invasion of the azooxanthellate coral Tubastraea (Scleractinia: Dendrophylliidae) throughout the world: history, pathways and vectors. Biol. Inv. 19, 283-305. doi: 10.1007/s10530-016-1279-y

Cuif, J.-P., Lecointre, G., Perrin, C., Tillier, A., and Tillier, S. (2003). Patterns of septal bio- mineralization in Scleractinia compared with their $28 \mathrm{~S}$ rRNA phylogeny: a dual approach for a new taxonomic framework. Zool. Scr. 32, 459-473. doi: 10.1046/j.1463-6409.2003.00133.x

De Cáceres, M., and Legendre, P. (2009). Associations between species and groups of sites: indices and statistical inference. Ecology 90, 3566-3574. doi: 10.1890/ 08-1823.1

Edgar, R. C. (2017). SEARCH_16S: A New Algorithm for Identifying 16S Ribosomal RNA gEnes in Contigs and Chromosomes. Available at: http://biorxiv.org/ content/early/2017/04/04/124131

Fine, M., and Loya, Y. (2002). Endolithic algae: an alternative source of photoassimilates during coral bleaching. Proc. R. Soc. Lond. B Biol. Sci. 269, 1205-1210. doi: 10.1098/rspb.2002.1983

Glasl, B., Bongaerts, P., Elisabeth, N. H., Hoegh-Guldberg, O., Herndl, G. J., and Frade, P. R. (2017). Microbiome variation in corals with distinct depth distribution ranges across a shallow-mesophotic gradient $(15-85 \mathrm{~m})$. Coral Reefs 36, 447-452. doi: 10.1007/s00338-016-1517-x

Glasl, B., Herndl, G. J., and Frade, P. R. (2016). The microbiome of coral surface ucus has a key role in mediating holobiont health and survival upon disturbance. ISME J. 10, 2280-2292. doi: 10.1038/ismej.2016.9

Hansson, L., Agis, M., Maier, C., and Weinbauer, M. G. G. (2009). Community composition of bacteria associated with cold-water coral Madrepora oculata: within and between colony variability. Mar. Ecol. Prog. Ser. 397, 89-102. doi: 10.3354/meps08429

Hernandez-Agreda, A., Leggat, W., Bongaerts, P., and Ainsworth, T. D. (2016). The microbial signature provides insight into the mechanistic basis of coral success across reef habitats. mBio 7:e00560-16. doi: 10.1128/mBio.00 560-16

Hoeksema, B., and ten Hove, H. (2017). The invasive sun coral Tubastraea coccinea hosting a native Christmas tree worm at Curaçao, Dutch Caribbean. Mar. Biodiv. 47, 59-65. doi: 10.1007/s12526-016-0472-7

Hyun, D.-W., Shin, N.-R., Kim, M.-S., Oh, S. J., Kim, P. S., Whon, T. W., et al. (2014). Endozoicomonas atrinae sp. nov., isolated from the intestine of a combpen shell Atrina pectinata. Int. J. Syst. Evol. Microbiol. 64, 2312-2318. doi: 10.1099/ijs.0.060780-0

Jessen, C., Villa, Lizcano JF, Bayer, T., Roder, C., Aranda, M., Wild, C., et al. (2013). In-situ effects of eutrophication and overfishing on physiology and bacterial diversity of the Red Sea coral Acropora hemprichii. PLoS One 8:e62091. doi: 10.1371/journal.pone.0062091

Keller, N. B. (1976). The deep-sea madreporarian corals of the genus Fungiacyathus from the Kuril-Kamchatka, Aleutian trenches and other regions of world ocean. Tr. Inst. Okeanologii 99, 31-44. 
Kirk, N. L., and Weis, V. M. (2016). "Animal-Symbiodinium symbioses: foundations of the coral reef ecosystems," in The Mechanistic Benefits of Microbial Symbionts, Advances in Environmental Microbiology, ed. C. J. Hurst (Berlin: Springer International Publishing).

Kitahara, M. V., Cairns, S. D., Stolarski, J., Blair, D., and Miller, D. J. (2010). A comprehensive phylogenetic analysis of the Scleractinia (Cnidaria, Anthozoa) based on mitochondrial CO1 sequence data. PLoS One 5:e11490. doi: 10.1371/ journal.pone.0011490

Kurahashi, M., and Yokota, A. (2007). Endozoicomonas elysicola gen. nov., sp. nov., a - proteobacterium isolated from the sea slug Elysia ornata. Syst. Appl. Microbiol. 30, 202-206. doi: 10.1016/j.syapm.2006.07.003

Lee, O. O., Yang, J., Bougouffa, S., Wang, Y., Batang, Z., Tian, R., et al. (2012). Spatial and species variations in bacterial communities associated with corals from the red sea as revealed by pyrosequencing. Appl. Environ. Microbiol. 78, 7173-7184. doi: 10.1128/AEM.01111-12

Lesson, R. P. (1830). “Zoophytes,” in Voyage Autour du Monde : Exécuté Par Ordre du Roi, Sur la Corvette de Sa Majesté, la Coquille, Pendant les Années, Vol. 2, ed. M. L.-J. Duperrey (Paris: Zoologie), 1822-1825.

Li, J., Chen, Q., Long, L.-J., Dong, J.-D., Yang, J., and Zhang, S. (2014). Bacterial dynamics within the mucus, tissue and skeleton of the coral Porites lutea during different seasons. Sci. Rep. 4:7320. doi: 10.1038/srep07320

Lindström, G. (1877). Contributions to the actinology of the Atlantic Ocean. K. svenska Vetensk.-Acad. Handl. 14, 1-26.

Littman, R. A., Bourne, D. G., and Willis, B. L. (2010). Responses of coral-associated bacterial communities to heat stress differ with Symbiodinium type on the same coral host. Mol. Ecol. 19, 1978-1990. doi: 10.1111/j.1365-294X.2010.04 620.x

Marcelino, V. R., and Verbruggen, H. (2016). Multi-marker metabarcoding of coral skeletocs reveals a rich microbiome and diverse evolutionary origins of endolithic algae. Sci. Rep. 6:31508. doi: 10.1038/srep31508

Meistertzheim, A.-L., Lartaud, F., Arnaud-Haond, S., Kalenitchenko, D., Bessalam, M., Le Bris, N., et al. (2016). Patterns of bacteria-host associations suggest different ecological strategies between two reef building cold-water coral species. Deep Sea Res. I 114, 12-22. doi: 10.1016/j.dsr.2016.04.013

Neave, M., Rachnawati, R., Xun, L., Michell, C., and Bourne, D. G. (2017). Differential specificity between closely related corals and abundant Endozoicomonas endosymbionts across global scales. ISME J. 11, 186-200. doi: 10.1038 /ismej.2016.95

Neave, M. J., Apprill, A., Ferrier-Pages, C., and Voolstra, C. R. (2016). Diversity and function of prevalent symbiotic marine bacteria in the genus Endozoicomonas. Appl. Microbiol. Biotechnol. 100, 8315-8324. doi: 10.1007/s00253-016-7777-0

Polónia, A. R. M., Clearly, D. F. R., Duarte, L. N., de Voogd, N. J., and Gomes, N. C. M. (2014). Composition of Archaea in seawater, sediment, and sponges in the Kepulauan Seribu reef system, Indonesia. Microb. Ecol. 67, 553-567. doi: 10.1007/s00248-013-0365-2

R Development Core Team (2013). A Language and Environment for Statistical Computing. Vienna: R Foundation for Statistical Computing. Available at: http: //www.R-project.org

Ravindran, J., Kannapiran, E., Manikandan, B., Francis, K., and Arora, S. (2013). UV-absorbing bacteria in coral mucus and their response to simulated temperature elevations. Coral Reefs 32, 1043-1050. doi: 10.1007/s00338-0131053-x

Ritchie, K. B. (2006). Regulation of microbial populations by coral surface mucus and mucus-associated bacteria. Mar. Ecol. Prog. Ser. 322, 1-14. doi: 10.3354/ meps322001

Roberts, J. M., Wheeler, A. J., Freiwald, A., and Cairns, S. D. (2009). Cold Water Corals: the Biology and Geology of Deep-Sea Coral Habitats. Cambridge: Cambridge University Press. doi: 10.1017/CBO9780511581588
Rodriguez-Lanetty, M., Granados-Cifuentes, C., Barberan, A., Bellantuono, A. J., and Bastidas, C. (2013). Ecological inferences from a deep screening of the complex bacterial consortia associated with the coral. Porites astreoides. Mol. Ecol. 22, 4349-4362. doi: 10.1111/mec.12392

Rohwer, F., Seguritan, V., Azam, F., and Knowlton, N. (2002). Diversity and distribution of coral-associated bacteria. Mar. Ecol. Prog. Ser. 243, 1-10. doi: 10.3354/meps 243001

Schreiber, L., Kjeldsen, K. U., Obst, M., Funch, P., and Schramm, A. (2016). Description of Endozoicomonas ascidiicola sp. nov., isolated from Scandinavian ascidians. Syst. Appl. Microbiol. 39, 313-318. doi: 10.1016/j.syapm.2016.05.008

Séré, M. G., Tortosa, P., Chabanet, P., Turquet, J., Quod, J.-P., and Schleyer, M. H. (2013). Bacterial communities associated with porites white patch syndrome (PWPS) on three Western Indian Ocean (WIO) coral reefs. PLoS One 8:e83746. doi: 10.1371/journal.pone.0083746

Shashar, N., Banaszak, A. T., Lesser, M. P., and Amrami, D. (1997). Coral endolithic algae: life in a protected environment. Pac. Sci. 51, 167-173.

Sheu, S. Y., Lin, K. R., Hsu, M. Y., Sheu, D. S., Tang, S. L., and Chen, W. M. (2017). Endozoicomonas acroporae sp. nov., isolated from Acropora coral. Int. J. Syst. Evol. Microbiol. 67, 3791-3797. doi: 10.1099/ijsem.0.002194

Sunagawa, S., Woodley, C. M., and Medina, M. (2010). Threatened corals provide underexplored microbial habitats. PLoS One 5:e9554. doi: 10.1371/journal. pone.0009554

Sweet, M. J., Croquer, A., and Bythell, J. C. (2010). Bacterial assemblages differ between compartments within the coral holobiont. Coral Reefs 30, 39-52. doi: 10.1007/s00338-010-0695-1

Vaughan, T. W., and Wells, J. W. (1943). Revision of the suborders, families and genera of the Scleractinia. Spec. Pap. Geol. Soc. Am. 44, 247-293.

Vezzulli, L., Pezzati, E., Huete-Stauffer, C., Pruzzo, C., and Cerrano, C. (2013). 16SrDNA pyrosequencing of the Mediterranean gorgonian Paramuricea clavata reveals a link among alterations in bacterial holobiont members, anthropogenic influence and disease outbreaks. PLoS One 8:e67745. doi: 10.1371/journal.pone. 0067745

Wang, Y., and Qian, P.-Y. (2009). Conservative fragments in bacterial 16S rRNA genes and primer design for 16S ribosomal DNA amplicons in metagenomic studies. PLoS One 4:e7401. doi: 10.1371/journal.pone.0007401

Wild, C., Huettel, M., Klueter, A., Kremb, S. G., Rasheed, M. Y. M., and Jorgensen, B. B. (2004). Coral mucus functions as an energy carrier and particle trap in the reef ecosystem. Nature 428, 66-70. doi: 10.1038/nature02344

Yang, S., Sun, W., Zhang, F., and Li, Z. (2013). Phylogenetically diverse denitrifying and ammonia-oxidizingbacteria in corals Alcyonium gracillimum and Tubastraea coccinea. Mar. Biotechnol. 15, 540-551. doi: 10.1007/s10 126-013-9503-6

Yuen, Y. S., Yamazaki, S. S., Baird, A. H., Nakaura, T., and Yamasaki, H. (2013). Sulfate-reducing bacteria in the skeleton of the massive coral Goniastrea aspera from the great barrier reef. Galaxea J. Coral Reef Stud. 15, 154-159. doi: 10. 3755/galaxea.15.154

Conflict of Interest Statement: The authors declare that the research was conducted in the absence of any commercial or financial relationships that could be construed as a potential conflict of interest.

Copyright (c) 2018 Engelen, Aires, Vermeij, Herndl, Serrão and Frade. This is an open-access article distributed under the terms of the Creative Commons Attribution License (CC BY). The use, distribution or reproduction in other forums is permitted, provided the original author(s) and the copyright owner(s) are credited and that the original publication in this journal is cited, in accordance with accepted academic practice. No use, distribution or reproduction is permitted which does not comply with these terms. 